\title{
Interaction between physical activity and outdoor time on allostatic load in Chinese college students
}

\author{
Dan Zhang 1,2,3,4, Tingting $\mathrm{Li}^{1,2,3,4}$, Yang Xie ${ }^{1,2,3,4}$, Shuman Tao5, Yajuan Yang ${ }^{6}$, Liwei Zou ${ }^{1,2,3,4}$, Yang Qu 1,2,3,4, \\ Shuang Zhai ${ }^{1,2,3,4}$, Fangbiao Tao ${ }^{1,2,3,4}$ and Xiaoyan $\mathrm{Wu}^{1,2,3,4^{*}}$
}

\begin{abstract}
Background: Physical activity (PA) deficiency, outdoor time reduction during college have been associated with higher cumulative physiological burden as measured by allostatic load (AL). Therefore, the present research sought to analyze the independent and interaction effects of PA and outdoor time on AL in college students.

Methods: A cross-sectional survey was conducted in two universities from April to May 2019. Self-assessment questionnaire and International Physical Activity Questionnaire Short Version (IPAQ-SF) were used in the investigation, AL level was assessed according to the results of biochemical examination, blood pressure and human body morphological measurements. Binary Logistic Analysis was used to analyze the relationships between PA, outdoor time and AL.
\end{abstract}

Results: The prevalence of low PA, low outdoor time and high AL were $16.3 \%, 71.1 \%$ and $47.6 \%$, respectively. Low PA $(O R=1.83,95 \% C l: 1.20 \sim 2.78)$ and low outdoor time $(O R=1.90,95 \% C l: 1.35 \sim 2.67)$ are independently associated with high $\mathrm{AL}(P<0.05$, for each). Interaction analysis indicated that low PA and low outdoor time were interactively associated with high $\mathrm{AL}(\mathrm{OR}=2.93$, 95\% Cl: 1.73 4.94, $P<0.05)$.

Conclusions: There were the significant independent and interaction effects between PA and outdoor time on AL. In the future, college students' physical education can be arranged reasonably to reduce the health risks.

Keywords: Allostatic load, Physical activity, Outdoor time, College student

\section{Introduction}

The concept of AL was introduced by McEwen and Stellar in 1993 [1] and it offers a comprehensive index for understanding how exposure to environmental stressors during development can lead to a result of multi-system maladjustment and poor health. As a comprehensive index [1], AL involves multi-system including the sympathetic adrenomedullary system (SAM), the hypothalamic pituitary adrenal (HPA) axis, indices of inflammation,

\footnotetext{
*Correspondence: xywu@ahmu.edu.cn

${ }^{1}$ Department of Maternal, Child and Adolescent Health, School of Public Health, Anhui Medical University, Hefei, China

Full list of author information is available at the end of the article
}

immune functioning, lipid metabolism and it's important to use clinimetric approach for a more comprehensive assessment of allostatic load and overload. Therefore, AL represents the cumulative effect of daily life experiences involving both ordinary events (long-standing life situations) and major challenges (life events), including the physiological consequences of resulting health damaging behaviors. Accordingly, when environmental challenges exceed the individual ability to cope, then allostatic overload will occur [1].

Most college students range in age from approximately 18 to 22 years, and college is therefore a transitional period from adolescence to adulthood. This age-span is a critical period for the development of healthy lifestyles 
and behaviors that are important throughout the lifespan [2]. However, under the double burden of study and life, the life style of college students has changed, which is characterized by less physical activities (PA), especially outdoor activities [2]. According to the latest World Health Organization (WHO) survey, about 80 per cent of adolescents worldwide do not meet the recommended level of PA per day [3].

In addition, numerous studies have shown that less PA is one of the important risk factors for health, less PA is associated with cardiovascular disease, type 2 diabetes, colon cancer, and other important diseases $[4,5]$. The health consequences of $\mathrm{PA}$ and outdoor time involve multiple physiological systems. Therefore, as a comprehensive index, AL can be used to measure the multisystem influence of PA and outdoor time on organism. Through the comprehensive index AL, we can understand that how PA and outdoor time gets under the skin to influence biological processes that are highly relevant to physical health and mental well-being.

While PA and outdoor time has been linked in several studies to metabolic, inflammation and cardiovascular risk among adolescent [6-8], no previous research directly examined the independent and interactional influences of PA and outdoor time on cumulative multisystem dysregulation among college studentsadolescent. Therefore, the present research first sought to analyze the independent effects of PA and outdoor time on AL in Chinese college students, and then sought to explore the interaction effects between PA and outdoor time on AL.

\section{Material and method}

\section{Study participants}

The subjects were from the College Student Behavior and Health Cohort Study, which is an ongoing cohort designed to focue on behaviors, physical and mental health in college students from the first year to the third year in China. Baseline data was analyzed in the present study. Firstly, between April to May 2019, two cities were selected by convenient sampling from Hefei, Anhui Province, and Shangrao, Jiangxi Province. Then, a medical university and a comprehensive normal university were selected based on stratified cluster sampling. We randomly selected two colleges from each university and surveyed all first-year students in each college. The baseline survey included electronic questionnaires scanned with smartphones and physical examination. We received a total of 1135 valid questionnaires that collected baseline information on sociodemographic and health-related factors, and the response rate was $98.6 \%$. In addition, 778 subjects underwent physical examinations, including biochemical examinations, blood pressure and human body morphological measurements.
The current study was approved by the Ethics Committee of Anhui Medical University (No. 20170291). Written informed consent was obtained from all of the participants. Free medical examination is available to all participants. The study excluded people who were taking medication or undergoing psychotherapy, the final sample was 729 college students.

\section{Sociodemographic Data}

Sociodemographic data for participants were collected by questionnaire, including age, gender (male or female), registered residential background (rural or urban), only child, parents' education level (less than high school degree or more), self-reported family economy (bad, general or good).

\section{Allostatic load}

The subjects of this study were sent to the local thirdclass hospitals for medical examination, measurement of height and weight using a fully automatic electronic height and weight meter. Height was measured to the nearest $0.1 \mathrm{~cm}$ and weight was measured to the nearest $0.1 \mathrm{~kg}$. BMI was calculated as weight in kilograms divided by the square of height in meters. Waist measurement is accurate to $0.1 \mathrm{~cm}$. The subjects had to rest for a few minutes before their blood pressure was measured, the resting blood pressure was then measured using an electronic sphygmomanometer. The subjects were given $5 \mathrm{ml}$ of fasting venous blood, then lipid/lipoprotein (cholesterol, high-density lipoprotein, low-density lipoprotein, triglyceride), fasting plasma glucose, insulin, and high sensitivity c-reactive protein were measured.

A total of 11 biomarkers from three types of biological systems were used to assess AL level of college students: Cardiovascular system (cholesterol, high-density lipoprotein, low-density lipoprotein, triglyceride, systolic and diastolic pressure); Metabolic system (waist circumference, BMI, insulin and fasting blood glucose); Immune system (high-sensitivity C-reactive protein). The blood pressure threshold was defined by the screening for elevated blood pressure among children and adolescents aged 7 18 years (WS/T 610-2018) [9] Waist circumference was defined by the high waist circumference screening threshold among children and adolescents aged 7 18 years (WS/T 611-2018) [10]. The threshold of BMI was defined by the screening for overweight and obesity among school-age children and adolescents (WS/T 5862018) [11]. The other biomarkers refer to the demarcation standard of AL index of college students by Currie $\mathrm{CL}$ et [12]. The specific threshold criteria are shown in Table 1.

Each biomarker is defined a value according to the threshold criteria, biomarkers above the threshold 
(high-density lipoprotein below the threshold) are defined a score of 1 . The total AL score was obtained by sum of 11 biomarkers, and the range of score was $0 \sim 11$. The higher the score, the more serious the physiological systems dysregulations was. In this study, AL score $<2$ was defined as low level and $\geq 2$ as high level [13]. outdoor time [16]. Weekday outdoor time was measured by"In the last 4 weeks, the average daily daytime outdoor time was minutes on weekdays?". Free day outdoor time was measured by "In the last 4 weeks, the average daily daytime outdoor time on the head without cover was ___ minutes on free days?"

Total outdoor time $=($ outdoor time on weekdays $\times 5+$ outdoor time on free days $\times 2) / 7$

\section{Physical activity}

The International Physical Activity Questionnaire Short Version (IPAQ-SF) was used to measure PA of college students in the past week $[14,15]$. PA level was divided into low physical activity (LPA $=3.3$ metabolicequivalent $[\mathrm{METs}]$ ), moderate physical activity (MPA $=4.0$ METs) and above.

A certain intensity of physical activity level $=$ the activity corresponding to the Met assigned value $\times$ weekly frequency $(d) \times$ daily time (min)

The criteria for low physical activity level are no physical activity reported or energy expenditure not enough to the MPA criteria. The moderate physical activity and above level is any combination of activities of three intensity ranges of at least $\mathrm{EE} \geq 600 \mathrm{MET} \mathrm{min} /$ week.

\section{Outdoor time}

Two questions from the Young Risk Behavior Surveillance System questionnaire were modified to measure

Table 1 Threshold criteria for AL biomarkers $(N=729)$

\begin{tabular}{|c|c|c|c|}
\hline \multirow[t]{2}{*}{ Variables } & \multirow[t]{2}{*}{ Means $\pm S D$} & \multicolumn{2}{|c|}{$\begin{array}{l}\text { Threshold } \\
\text { criteria for AL } \\
\text { biomarkers }\end{array}$} \\
\hline & & Males & Females \\
\hline \multicolumn{4}{|l|}{ Cardiovascular } \\
\hline Cholesterol (mmol/L) & $4.08 \pm 0.69$ & $\geq 6.10$ & $\geq 6.20$ \\
\hline High-density lipoprotein (mmol/L) & $1.44 \pm 0.27$ & $\leq 1.22$ & $\leq 1.45$ \\
\hline Low-density lipoprotein (mmol/L) & $2.08 \pm 0.50$ & $>2.76$ & $>2.82$ \\
\hline Triglyceride (mmol/L) & $0.89 \pm 0.44$ & $>2.16$ & $>1.67$ \\
\hline Systolic pressure (mm Hg) & $115.13 \pm 12.89$ & $>140$ & $>140$ \\
\hline Diastolic pressure $(\mathrm{mm} \mathrm{Hg})$ & $70.93 \pm 9.08$ & $>90$ & $>90$ \\
\hline \multicolumn{4}{|l|}{ Metabolic } \\
\hline Waist circumference $(\mathrm{cm})$ & $71.05 \pm 7.80$ & $>83.0$ & $>76.1$ \\
\hline $\mathrm{BMI}\left(\mathrm{kg} / \mathrm{m}^{2}\right)$ & $20.71 \pm 2.57$ & $>23.8$ & $>23.9$ \\
\hline Insulin (ulU/mL) & $5.46 \pm 4.56$ & $>20$ & $>20$ \\
\hline Fasting blood glucose (mmol/L) & $4.55 \pm 0.41$ & $>5.8$ & $>5.5$ \\
\hline \multicolumn{4}{|l|}{ Immune } \\
\hline $\begin{array}{l}\text { High-sensitivity C-reactive protein } \\
(\mathrm{mg} / \mathrm{L})\end{array}$ & $1.12 \pm 2.02$ & $\geq 8$ & $\geq 8$ \\
\hline Total AL score & $1.59 \pm 1.16$ & & \\
\hline
\end{tabular}

BMI Body Mass Index, AL Allostatic load, SD Standard Deviation
Referring to the Action for a healthy China (2019) [17], the study subjects were divided into two groups with $2 \mathrm{~h}$ as the cut-off value, $\geq 2 \mathrm{~h}$ as the high level, $<2 \mathrm{~h}$ as the low level.

\section{Covariates}

Health behaviors included cigarette use, alcohol use, quality of sleep and symptoms of depression. Two questions from the Young Risk Behavior Surveillance System questionnaire were modified to measure current cigarette and alcohol use. Cigarette use was measured by "How many days did you smoke during the past month?" Alcohol use was measured by "How many days did you have at least one drink during the past month?" The answers are recoded into "yes" or "no". Quality of sleep was assessed by the Pittsburgh Sleep Quality Index (PSQI).

\section{Statistical analysis}

Statistical analysis was performed using SPSS version 23.0 (Statistical Package for the Social Sciences). The Chi-square test was performed to compare the incidence of AL level among different sociodemographic variables, PA, and outdoor time. Binary logistic analysis was used to analyze the relationships between PA, outdoor time and AL. Odds ratios (ORs) and 95\% confidence intervals (95\%CIs) were calculated for the explanatory factors and adjusted for confounding factors, including quality of sleep, sex, smoking and self-reported family economy. Statistical significance was set at $P<0.05$.

\section{Results}

\section{Characteristics of participants}

Table 2 depicts the sample characteristics. There were responses from 729 college students aged between 16 and 22 years old (mean $\pm S D: 19.0 \pm 3.07$ years), 237 were males $(32.5 \%)$ and 492 were females $(67.5 \%)$. The high level of AL was detected in 47.6\% (347/729) of college students, female students' AL level higher than males $(P<0.05)$. College students with higher economic status were more likely to experience higher level of $\mathrm{AL}$ 
Table 2 Distribution of demographics characteristics of college students $(N=729)$

\begin{tabular}{|c|c|c|c|c|}
\hline \multirow[t]{2}{*}{ Variables } & \multicolumn{2}{|l|}{ AL level } & \multirow[t]{2}{*}{$x^{2}$} & \multirow[t]{2}{*}{$P$ value } \\
\hline & Low $(n=382)$ & High $(n=347)$ & & \\
\hline Gender & & & 14.21 & $<0.001$ \\
\hline Males & $148(62.4)$ & $89(37.6)$ & & \\
\hline Females & $234(47.6)$ & $258(52.4)$ & & \\
\hline Registered residence & & & 0.41 & 0.524 \\
\hline Rural & $209(51.4)$ & 198 (48.6) & & \\
\hline Urban & $173(53.7)$ & $149(46.3)$ & & \\
\hline Only child & & & 0.18 & 0.670 \\
\hline Yes & $96(51.1)$ & $92(48.9)$ & & \\
\hline No & $286(52.9)$ & $255(47.1)$ & & \\
\hline Paternal education & & & 0.24 & 0.622 \\
\hline$<12$ years & $338(52.1)$ & $311(47.9)$ & & \\
\hline$\geq 12$ years & $44(55.0)$ & $36(45.0)$ & & \\
\hline Maternal education & & & 0.40 & 0.526 \\
\hline$<12$ years & $358(52.1)$ & $329(47.9)$ & & \\
\hline$\geq 12$ years & $24(57.1)$ & $18(42.9)$ & & \\
\hline $\begin{array}{l}\text { Household economic } \\
\text { status }\end{array}$ & & & 8.77 & 0.012 \\
\hline High & $12(30.0)$ & $28(70.0)$ & & \\
\hline Moderate & $289(54.2)$ & $244(45.8)$ & & \\
\hline Low & $81(51.9)$ & $75(48.1)$ & & \\
\hline Cigarette use & & & 18.83 & $<0.001$ \\
\hline Yes & $39(83.0)$ & $8(17.0)$ & & \\
\hline No & $343(50.3)$ & $339(49.7)$ & & \\
\hline Alcohol use & & & 3.82 & 0.051 \\
\hline Yes & $92(59.4)$ & $63(40.6)$ & & \\
\hline No & $290(50.5)$ & $284(49.5)$ & & \\
\hline Quality of sleep & & & 0.027 & 0.871 \\
\hline High & $334(52.5)$ & $302(47.5)$ & & \\
\hline Low & $48(51.6)$ & $45(48.4)$ & & \\
\hline
\end{tabular}

The figures in () are composition ratio or detection rate/\%

AL Allostatic load

$(P<0.05)$. Compared with smokers, non-smoking college students showed higher levels of AL $(P<0.05)$.

\section{The Distribution Characteristics of PA and Outdoor Time}

Table 3 depicts the distribution characteristics of PA and outdoor time. College students who were low PA reported higher rates of AL (58.8\% VS 45.4\%, respectively, $P=0.007)$. Higher rates of AL were also observed in those with low level of outdoor time $(52.9 \% \mathrm{VS}$ $34.6 \%$, respectively, $P<0.001)$. Further analysis of work days and free days shows that college students who were low free day outdoor time $(51.0 \%$ VS $38.4 \%$, respectively, $P=0.002$ ) or low work day outdoor time (52.9\% VS 28.8\%, respectively, $P<0.001$ ) reported higher rates of AL.
Table 3 Detection rate of $\mathrm{AL}$ level in college students of different outdoor time and PA

\begin{tabular}{|c|c|c|c|c|}
\hline \multirow[t]{2}{*}{ Variables } & \multicolumn{2}{|l|}{ AL level } & \multirow[t]{2}{*}{$x^{2}$} & \multirow[t]{2}{*}{$P$ value } \\
\hline & $\operatorname{Low}(n=382)$ & High $(n=347)$ & & \\
\hline Total outdoor time & & & 20.13 & $<0.001$ \\
\hline High & $138(65.4)$ & $73(34.6)$ & & \\
\hline Low & $244(47.1)$ & $274(52.9)$ & & \\
\hline Free day outdoor time & & & 9.26 & 0.002 \\
\hline High & $122(61.6)$ & $76(38.4)$ & & \\
\hline Low & $260(49.0)$ & $271(51.0)$ & & \\
\hline Work day outdoor time & & & 29.20 & $<0.001$ \\
\hline High & $114(71.3)$ & $46(28.8)$ & & \\
\hline Low & $268(47.1)$ & $301(52.9)$ & & \\
\hline PA & & & 7.18 & 0.007 \\
\hline Moderate and above & $333(54.6)$ & $277(45.4)$ & & \\
\hline Low & $49(41.2)$ & $70(58.8)$ & & \\
\hline
\end{tabular}

Associations of PA, outdoor time and AL

After adjusting for confounding factors including sex, smoking and self-reported family economy, results from binomial logistic regression analysis showed that low PA $(O R=1.83,95 \% C I: 1.20 \sim 2.78)$ and low outdoor time $(O R=1.90,95 \% C I: 1.35 \sim 2.67)$ are independently associated with high AL $(P<0.05$, for each, Table 4$)$. Then, we stratified the data based on work day, free day, the results showed that both work day outdoor time $(O R=2.41$, $95 \% C I: 1.63 \sim 3.58)$ and free day outdoor time $(O R=1.51$,

Table 4 Logistic regression analysis of outdoor time, PA level and AL of college students

\begin{tabular}{|c|c|c|c|c|}
\hline \multirow[t]{2}{*}{ Variables } & \multicolumn{2}{|l|}{ Crude MODEL } & \multicolumn{2}{|c|}{ Adjusted MODEL ${ }^{a}$} \\
\hline & OR $(95 \% C l)$ & $P$ value & OR $(95 \% C l)$ & $P$ value \\
\hline \multicolumn{5}{|c|}{ Total outdoor time } \\
\hline High & 1 & & 1 & \\
\hline Low & $2.12(1.52 \sim 3.00)$ & $<0.001$ & $1.90(1.35 \sim 2.67)$ & 0.001 \\
\hline \multicolumn{5}{|c|}{ Free day outdoor time } \\
\hline High & 1 & & 1 & \\
\hline Low & $1.67(1.20 \sim 2.34)$ & 0.002 & $1.51(1.07 \sim 2.12)$ & 0.019 \\
\hline \multicolumn{5}{|c|}{ Work day outdoor time } \\
\hline High & 1 & & 1 & \\
\hline Low & $2.78(1.90 \sim 4.07)$ & $<0.001$ & $2.41(1.63 \sim 3.58)$ & $<0.001$ \\
\hline \multicolumn{5}{|l|}{ PA } \\
\hline $\begin{array}{l}\text { Moderate } \\
\text { and above }\end{array}$ & 1 & & 1 & \\
\hline Low & $1.72(1.15 \sim 2.56)$ & 0.008 & $1.83(1.20 \sim 2.78)$ & 0.005 \\
\hline
\end{tabular}


95\%CI: $1.07 \sim 2.12)$ are independently positively associated with $\operatorname{AL}(P<0.05$, for each, Table 4 , Fig. 1$)$.

\section{Interactions of PA, and outdoor time with $\mathrm{AL}$}

The results of regression analyses examining the interactions of PA and outdoor time with AL were shown in Table 5. Table 5 shows crude and adjusted OR $(95 \% C I)$ for AL in those with low PA or low outdoor time, low PA or high outdoor time, high PA or low outdoor time compared with the reference group (high PA or high outdoor time). There was a positive interaction effects between PA and outdoor time on AL $(P<0.05)$, low PA college student with low outdoor time were more likely to be with high $\mathrm{AL}(O R=3.07,95 \% C I$ : 1.86 5.07). After adjusting for confounding factors, the positive interaction effects remained significant $(O R=2.93, \quad 95 \% C I: \quad 1.73 \sim 4.94$, $P<0.05$ ) (Table 5).

\section{Discussion}

This study assessed, for the first time, the independent and interaction effects between PA and outdoor time on AL, a measure of biological multi-system dysregulation among a sample of 729 Chinese college students. The prevalence of low PA, low outdoor time and high AL were $16.3 \%, 71.1 \%$ and $47.6 \%$, respectively. Participants with low PA and outdoor time exhibit higher AL.

We observed that $16.3 \%$ and $71.1 \%$ of the participants had low PA and low outdoor time, which was similar to Brazilian adolescents (PA: 16.2\%) [18] and slightly lower than Chinese rural adolescents (outdoor time: 82.0\%) [19]. PA deficiency and outdoor time reduction of college students is a common phenomenon, which has become a public health problem all over the world, which may be related to heavy academic load and too much sedentary time of college students.

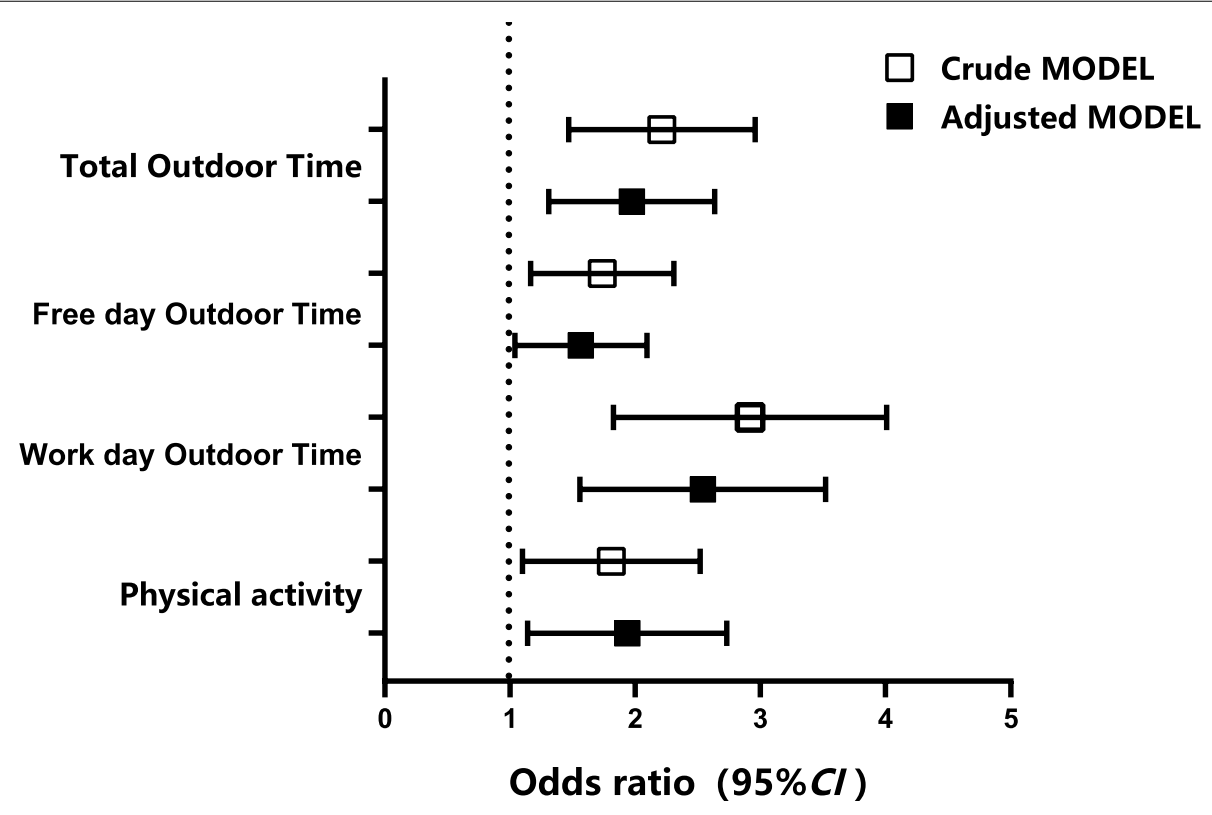

Fig. 1 Associations of Physical activity, outdoor time and Allostatic Load

Table 5 Interactions of PA, Outdoor time and AL in College Students

\begin{tabular}{|c|c|c|c|c|c|c|}
\hline \multirow[t]{2}{*}{ Outdoor time $\times \mathrm{PA}$} & \multicolumn{3}{|c|}{ Crude MODEL } & \multicolumn{3}{|c|}{ Adjusted MODEL ${ }^{a}$} \\
\hline & $B$ & OR $(95 \% \mathrm{Cl})$ & $P$ value & $B$ & OR $(95 \% \mathrm{Cl})$ & $P$ value \\
\hline High $\times$ Moderate and above & 1 & & & 1 & & \\
\hline High $\times$ Low & 0.93 & $2.54(1.00 \sim 6.46)$ & 0.050 & 1.10 & $3.01(1.14 \sim 7.99)$ & 0.027 \\
\hline Low $\times$ Moderate and above & 0.79 & $2.19(1.53 \sim 3.14)$ & $<0.001$ & 0.67 & $1.96(1.14 \sim 2.84)$ & 0.001 \\
\hline Low $\times$ Low & 1.12 & $3.07(1.86 \sim 5.07)$ & $<0.001$ & 1.07 & $2.93(1.73 \sim 4.94)$ & $<0.001$ \\
\hline
\end{tabular}

AL allostatic load, $P A$ physical activity, 95\%Cl 95\% confidence interval, OR odds ratio

a Adjusted MODEL controlled quality of sleep, household finances, gender and smoking 
We investigated high AL in $47.6 \%$ of participants, which was the same as Calcaterra V's investigation (53.6\%) [20]. However, another study in the United States [21] showed that the detection rate of high level (score $\geq 2$ ) of AL among college students was $79 \%$, which was higher than our study. More than half of college students are at $\mathrm{Al}$ high level, which may be due to insufficient physical activity and lack of outdoor time [22, 23].

\section{Independent effects}

Previous studies have also explored the relationship between PA and outdoor time and AL. Forrester SN et al. reported that moderate to high PA was beneficial for lower AL [22]. Findings from the Generation XXI birth cohort revealed that negative association between outdoor time and $\mathrm{AL}$ in adolescence, suggesting that the exposure of green environment may contribute to improve adolescent health [23]. D'Alessio et al. also discusses the beneficial effects of yoga as a kind of PAs on physical health and the reduction of AL [24]. Thus, it can be inferred that low PA and low outdoor time exposure can lead to elevated levels of AL in college students, leading to increased health risks.

In addition, in our study, we didn't find a difference in the relationship between free day outdoor time, work day outdoor time, and AL levels. We not only observed a positive association between short free day outdoor time and high AL, but also observed a positive association between work day outdoor time and Al. It's the opposite of a study of rural Chinese teenagers [25], work day outdoor time was associated with cardiovascular and metabolic health, while free day outdoor time was not found to be associated. It possibly because college students have more freedom to schedule outdoor time on work days and free days.

\section{Interaction effects}

Although there have been a few studies have illuminated significant independent effects between PA and outdoor time on AL. Yet study on the interaction effects of PA and outdoor time on AL is lacking. In fact, increasing outdoor time has been shown to be an important strategy for increasing PA levels, increasing the outdoor time and the level of PA the same time have a more obvious impact on the health of the body [4]. A systematic review by Thompson Cocoon $J$ et al. suggests that the health benefits of PA outdoors are greater than those of PA indoors [26].

The review from Gorman $\mathrm{S}$ et al. indicated that outdoor time could synergise with physical activity to prevent metabolic dysfunction, particularly that related to lifestyle diseases of obesity, type 2 diabetes and metabolic syndrome [27]. A series of new studies have shown that outdoor physical activity has varying degrees of impact on metabolism, cardiovascular and immune systems [28, 29], which can be used as indirect evidence to support the effect of PA and outdoor time interaction on AL. In the meantime, our study provides further evidence of the positive interaction effect between low PA and low outdoor time on AL and produce the different degree influence to the organism each physiological system.

\section{Biological mechanism}

AL reflects the cumulative effect of stress in daily life, as a multi-system comprehensive index, it can be used as an early predictor of poor health or function. Our study found a correlation between AL and PA and outdoor time, which were generally consistent with emerging evidence from research on physical fitness development of adolescent [29], research on PA outdoor of college students suggesting that low level of PA and outdoor time could have an adverse effect on physical health and appeared to be associated with increased activation in the nervous, cardiometabolic and immune systems.

The present research adds to a growing base of evidence that suggests positive PA and outdoor time act as mechanisms that modify biological pathways associated with health risk. Chung WK et al. reported that low level PA outdoor adolescents be associated with higher BMI among a prospective study of the Netherlands [30]. A recent intervention study from Wuhan, China, revealed that PA outdoor improves the metabolic profile, cardiorespiratory fitness and insulin sensitivity in university students [31]. Contrepois $\mathrm{K}$ et al. conducted a study on the biological effects of PA on cardiovascular, metabolic and immune pathways. The results showed that, PA is associated with inflammatory response [32]. Less PA induced an undesirable inflammatory response with increased transcripts of 'B cell receptor', 'NF-kB signaling' and many interleukin signaling pathways. They also detected many pathways associated with cardiovascular related signaling highlighting the correlation between PA and cardiovascular health. As our research has shown that low PA and outdoor time exposure can affect physiological processes in college students.

\section{Research Prospect}

Studies are now increasingly reporting on allostatic load in younger populations, including children and adolescents [12]. However, elderly people have higher AL levels than other groups due to their lack of physical activity and outdoor time in old age, as well as long-term experience of various chronic stresses. Therefore, in the future, researchers can further explore the impact of PA and outdoor time on other populations, especially the elderly AL. 


\section{Limitations and Strengths}

Some aspects of the study constitute possible limitations. First, the cross-sectional analysis precludes causal interpretation, and further longitudinal studies are needed to establish a causal relationship between PA and outdoor time and Al. Second, there are confounding factors including neighborhood quality, whichcontribute to AL that may not have been measured and included in analyses. Third, this study used self-report to evaluate the PA and outdoor time, so it may not be able to avoid reporting bias; however, the large sample size available for analysis reduces the likelihood of this having a meaningful impact on the results presented here. At last, the study objects were all college students, which have their own group characteristics, so the study may have selection bias, the results of the study to the general population extrapolation may be limited. However, these data were randomly selected which allows control for socioeconomic confounders and provides strong support for an association between PA, outdoor time and AL. Despite these limitations, this study makes several contributions that could have important implications. Our study uses AL as a comprehensive index to objectively and quantitatively evaluate the biological functions of multiple systems, which is superior to single-dimensional biomarkers. This study also addresses a gap in the literature by examining the independent and interaction effects between PA and outdoor time on AL in college student. Last but not least, we focus on the health risks of college students and emphasize the impact of early risk exposure on the whole life cycle.

\section{Conclusions}

In our study, PA and outdoor time are cross-sectional associated with AL, with interactions of PA and outdoor time on AL. This research extends previous findings on the detrimental effects of PA and outdoor time by exploring and proposing a biological mechanism by which it exert effects on physical health. In the future, college students' physical education can be arranged reasonably, and outdoor activities can be advocated to reduce the health risks of college students.

\section{Acknowledgments}

We thank Lili Pan, Yunfeng Zhao, Jinkui Lu, Jianmin Xiang, and Yongsheng Xu for assisting with data collection. We acknowledge the participants for their dedication and cooperation while participating in this research project.

\section{Disclosure statement}

All authors who contributed to the manuscript gave their approval for its submission to BMC PUBLIC HEALTH. The work presented here has not been published previously and is not being considered for publication elsewhere. The author(s) read and approved the final manuscript.

\section{Authors' contributions}

$X W$ and $F T$ conceived and designed the experiments. ST and $Y Y$ performed the experiments.DZ, YQ, SZ, TL, YX, and LZ analyzed the data. DZ wrote the paper. DZ contributed to study design. The author(s) read and approved the final manuscript.

\section{Funding}

This work was supported by the National Natural Science Foundation of China (Grant Nos. 82173542) and the Key Project for University Talents from the Education Bureau of Anhui Province, China (Grant No. gxyqZD2020011). These institutions had no further role in the study design, the collection and analysis of data, the report's writing, and the decision to submit the paper for publication.

\section{Availability of data and materials}

The datasets generated and analysed during the current study are not publicly available because the author does not have permission to share the data but are available from the corresponding author on reasonable request.

\section{Declarations}

\section{Ethics approval and consent to participate}

All procedures performed in studies involving human participants were in accordance with the ethical standards of the institutional and/or national research committee (Ethics Committee of Anhui Medical University, China; NO.20170291). The design and data collection were reviewed and approved by the Ethics Committee of Anhui Medical University, China (NO.20170291). All participants wrote informed consent for inclusion prior to the administration of the survey.

\section{Consent for publication}

Not applicable.

\section{Competing interests}

The authors declare no conflict of interest.

\section{Author details}

${ }^{1}$ Department of Maternal, Child and Adolescent Health, School of Public Health, Anhui Medical University, Hefei, China. ${ }^{2}$ MOE Key Laboratory of Population Health Across Life Cycle, Hefei, China. ${ }^{3} \mathrm{NHC}$ Key Laboratory of Study on Abnormal Gametes and Reproductive Tract, Hefei, China. ${ }^{4}$ Anhui Provincial Key Laboratory of Population Health and Aristogenics, Anhui Medical University, Hefei, China. ${ }^{5}$ The Second Hospital of Anhui Medical University, Hefei, China. ${ }^{6}$ School of Nursing, Anhui Medical University, Hefei, China.

Received: 24 September 2021 Accepted: 31 December 2021

Published online: 27 January 2022

\section{References}

1. McEwen BS, Stellar E. Stress and the individual. Mechanisms leading to disease. Arch Intern Med. 1993;153(18):2093-101.

2. Hutchesson MJ, Duncan MJ, Oftedal S, Ashton LM, Oldmeadow C, KayLambkin F, et al. Latent class analysis of multiple health risk behaviors among Australian university students and associations with psychological distress. Nutrients. 2021;13(2):425.

3. Guthold R, Stevens GA, Riley LM, Bull FC. Global trends in insufficient physical activity among adolescents: a pooled analysis of 298 populationbased surveys with 1.6 million participants. Lancet Child Adolesc Health. 2020;4(1):23-35.

4. Gray C, Gibbons R, Larouche R, Sandseter EB, Bienenstock A, Brussoni M, et al. What is the relationship between outdoor time and physical activity, sedentary behaviour, and physical fitness in Children. A systematic review. Int J Environ Res Public Health. 2015;12(6):6455-74.

5. Aune D, Schlesinger S, Leitzmann MF, Tonstad S, Norat T, Riboli E, et al. Physical activity and the risk of heart failure: a systematic review and dose-response meta-analysis of prospective studies. Eur J Epidemiol. 2021;36(4):367-81. 
6. Harada K, Lee S, Lee S, Bae S, Harada K, Suzuki T, et al. Objectively-measured outdoor time and physical and psychological function among older adults. Geriatr Gerontol Int. 2017;17(10):1455-62.

7. Gorman S, Larcombe AN, Christian HE. Exposomes and metabolic health through a physical activity lens: a narrative review. J Endocrinol. 2021;249(1):R25-41.

8. Chen ST, Stevinson C, Yang CH, Sun WJ, Chen L, Ku PW. Cross-sectional and longitudinal associations of outdoor walking with overall mental health in later life. Exp Gerontol. 2021:151:111428.

9. National Health and Family Planning Commission. Screening for elevated blood pressure among children and adolescents aged 7 18 years, 2018. http://www.nhc.gov.cn/wjw/pqt/201807/6cee88c1d050493ab50a411a2 978f901.shtml

10. National Health and Family Planning Commission. Screening for overweight and obesity among school-age children and adolescents, 2018. http://www.nhc.gov.cn/wjw/pqt/201807/417de6982ab8493b91aba925b 51a8a19.shtml

11. National Health and Family Planning Commission. Screening for overweight and obesity among school-age children and adolescents, 2018. http://www.chinanutri.cn/fgbz/fgbzhybz/201804/t20180418_162494. html

12. Currie CL, Motz T, Copeland JL. The impact of racially motivated housing discrimination on allostatic load among Indigenous university students. $J$ Urban Health. 2020;97(3):365-76.

13. Theall KP, Drury SS, Shirtcliff EA. Cumulative neighborhood risk of psychosocial stress and allostatic load in adolescents. Am J Epidemiol. 2012:176:164-74.

14. Ács P, Veress R, Rocha P, Dóczi T, Raposa BL, Baumann P, et al. Criterion validity and reliability of the International Physical Activity QuestionnaireHungarian short form against the RM42 accelerometer. BMC Public Health. 2021:21:381

15. Nguyen LTK, Do BN, Vu DN, Pham KM, Vu MT, Nguyen HC, et al. Physical activity and diet quality modify the association between comorbidity and disability among stroke patients. Nutrients. 2021;13(5):1641.

16. Bull FC, Al-Ansari SS, Biddle S, Borodulin K, Buman MP, Cardon G, et al. World Health Organization 2020 guidelines on physical activity and sedentary behaviour. Br J Sports Med. 2020;54(24):1451-62.

17. National Board of Health, Healthy China Initiative (2019 2030)[ EB/OL ]. [2020-03-09]. http://www.gov.cn/xinwen/2019-07/15/content_5409694. htm

18. Cheng LA, Mendonça G, Farias Júnior JC. Physical activity in adolescents: analysis of the social influence of parents and friends. J Pediatr. 2014;90(1):35-41.

19. Zhao Y, Guo Y, Xiao Y, Zhu R, Sun W, Huang W, et al. The Effects of Online Homeschooling on Children, Parents, and Teachers of Grades 1-9 During the COVID-19 Pandemic. Med Sci Monit. 2020:26:e925591.

20. Calcaterra V, Vinci F, Casari G, Pelizzo G, de Silvestri A, De Amici M, et al. Evaluation of allostatic load as a marker of chronic stress in children and the importance of excess weight. Front Pediatr. 2019;7:335.

21. Currie CL, Copeland JL, Metz GA. Childhood racial discrimination and adult allostatic load: The role of Indigenous cultural continuity in allostatic resiliency. Soc Sci Med. 2019;241:112564.

22. Forrester SN, Leoutsakos JM, Gallo JJ, Thorpe RJ Jr, Seeman TE. Association between allostatic load and health behaviours: a latent class approach. J Epidemiol Community Health. 2019;73(4):340-5.

23. Ribeiro Al, Tavares C, Guttentag A, Barros H. Association between neighbourhood green space and biological markers in school-aged children. Findings from the Generation XXI birth cohort. Environ Int. 2019;132:105070

24. D'Alessio L, Korman GP, Sarudiansky M, Guelman LR, Scévola L, Pastore $A$, et al. Reducing allostatic load in depression and anxiety disorders: physical activity and yoga practice as add-on therapies. Front Psychiatry. 2020;11:501.

25. Zhang $Y$, Zhang $X$, Li J, Zhong H, Pan CW. Associations of outdoor activity and screen time with adiposity: findings from rural Chinese adolescents with relatively low adiposity risks. BMC Public Health. 2020;20(1):1769.

26. Thompson Coon J, Boddy K, Stein K, Whear R, Barton J, Depledge MH. Does participating in physical activity in outdoor natural environments have a greater effect on physical and mental wellbeing than physical activity indoors? A systematic review. Environ Sci Technol. 2011:45(5):1761-72
27. Gorman S, Larcombe AN, Christian HE. Exposomes and metabolic health through a physical activity lens: a narrative review. J Endocrinol. 2021;249(1):R25-41.

28. Mendoza MVF, Kachur SM, Lavie CJ. The effects of exercise on lipid biomarkers. Methods Mol Biol. 2022;2343:93-117.

29. Joensuu L, Kujala UM, Kankaanpää A, Syväoja HJ, Kulmala J, Hakonen $\mathrm{H}$, et al. Physical fitness development in relation to changes in body composition and physical activity in adolescence. Scand J Med Sci Sports. 2021;31(2):456-64

30. Chung WK, De Vos-Jakobs S, Rivadeneira F, Bierma-Zeinstra SM, Waarsing $\mathrm{JH}$. The association of BMl and physical activity on acetabular dysplasia in children. Osteoarthr Cartil. 2021;29(1):50-8.

31. Yu HJ, Li F, Hu YF, Li CF, Yuan S, Song Y, et al. Improving the metabolic and mental health of children with obesity: a school-based nutrition education and physical activity intervention in Wuhan, China. Nutrients. 2020;12(1):194.

32. Contrepois K, Wu S, Moneghetti KJ, Hornburg D, Ahadi S, Tsai MS, et al. Molecular choreography of acute exercise. Cell. 2020;181(5):1112-30.

\section{Publisher's Note}

Springer Nature remains neutral with regard to jurisdictional claims in published maps and institutional affiliations.

Ready to submit your research? Choose BMC and benefit from

- fast, convenient online submission

- thorough peer review by experienced researchers in your field

- rapid publication on acceptance

- support for research data, including large and complex data types

- gold Open Access which fosters wider collaboration and increased citations

- maximum visibility for your research: over $100 \mathrm{M}$ website views per year

At BMC, research is always in progress.

Learn more biomedcentral.com/submissions 